\title{
Patient-Centered Additional Offers in Breast Centers
}

\author{
Wolfgang Jannia Volker Hanf ${ }^{b}$ \\ aFrauenklinik, Universitätsklinikum UIm,

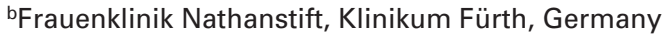

Based on clinical evidence gained primarily in prospective randomized trials, several national and international breast cancer treatment guidelines have been developed and are updated regularly. Internationally recognized guidelines, such as NCCN, NICE or the German recommendations of the AGO (Working Group Gynecologic Oncology), as well as Consensus Conference recommendations, such as those of the St. Gallen Conference on Primary Breast Cancer or the Lisbon Consensus Conference on Advanced Breast Cancer, have continuously developed a 'global perspective' on the treatment of breast cancer, despite regional differences in health systems and ethnicities. A number of recent publications demonstrated that guideline-adherent treatment significantly improves the outcome of breast cancer patients.

The traditional understanding of breast cancer as a primarily local disease has undergone fundamental changes in the last few decades, bringing forth the concept of early microdissemination deciding the fate of the patient. This changing view led to substantially reduced local radicality of surgical procedures, with breast operations now being reduced to a minimum by the use of breast-conserving surgery and axillary sentinel lymph node excision, omitting axillary clearing even in cases with limited node involvement. The now very common use of pathway-targeted, cytostatic, and endocrine systemic therapeutic modalities has developed into the second main treatment avenue besides local treatment. These systemic treatment options were tested and validated in large clinical trials, are now based on the best available evidence, and have been made available to the treating physician in the form of evidence-based guidelines. Overviews, such as those of the Early Breast Cancer Trialists' Collaborative Group, clearly demonstrated that these guideline-driven treatment improvements have translated into substantial survival gains.

However, treatment reality does not only consist of evidence-based and guideline-adherent treatment strategies, but is inevitably connected with patient-centered additional offers many clinicians are hardly aware of. Despite the fact that up to approximately $70 \%$ of our breast cancer patients will pursue additional offers and almost all our patients seek possibilities to regain treatment autonomy and actively influence the course of their disease, little attention is paid to offers outside the range of prospective randomized trials and scientific evidence. Following the principle 'what shall not be, that will not be', many health care professionals, especially in academic institutions, ignore the fact that the vast majority of patients actively seek patient-centered additional offers and educate themselves in various aspects of complementary and alternative medicine.

However, ignoring this fact, in our view, would disregard the center of all our therapeutic efforts: the patient. While guideline-adherent treatment should and hopefully will always be the mainstay of our daily practice, we should also pay attention to our patients' additional needs and offers which might play - at least in many patients' individual perspective - an equally important role as compared to questions of surgical technique or systemic therapy. The focus of this issue attempts to critically review patient-centered additional offers and put them into context of current guidelines, thus reaching out from evidence-based standard treatment as the mainstay of our conviction to our patients' treatment reality.

\section{KARGER \\ Fax +497614520714 \\ Information@Karger.com}

www.karger.com (c) 2013 S. Karger GmbH, Freiburg

$1661-3791 / 13 / 0085-0329 \$ 38.00 / 0$

Accessible online at:

www.karger.com/brc
Prof. Dr. med. Volker Hanf

Frauenklinik mit Nathanstift

Klinikum Fürth

Jakob-Henle-Straße 1, 90766 Fürth (Germany)

Volker.Hanf@klinikum-fuerth.de 